\title{
On The Necessity Of The Best Possible World
}

\author{
Keywords:
}

Optimism, Best Possible World, Leibniz, God, Necessity, Possibility

\begin{abstract}
:
Many have argued that if God exists then he must necessarily create the best possible world (hereafter: bpw), which entails that the bpw necessarily exists, and is therefore the only possible world. But without any scope for comparison, the superlative term 'best' is clearly inappropriate and so the bpw cannot be the bpw at all! As such, it must be impossible for God to create it. Hence if God exists then he must of necessity make something that is impossible to create! Because of its conclusion, I call this the repugnant argument. I consider a number of possible responses to this argument.
\end{abstract}

\section{The Problem Stated}

A few dissenters aside, the majority of philosophers who have expressed a view on the matter are firmly of the opinion that, if God exists, then he must make the best of all possible worlds. ${ }^{1}$ This is generally held to be true since God's omniscience leads him to know what is most perfect, his omnipotence enables him to bring it about, and his perfect goodness ensures that he would not even countenance acting in a less than perfect way. From this it follows that a most perfect being cannot operate in a less than perfect way. That is to say, God's nature is such that only the most perfect way of acting is consistent with it. This can be summed up in the following proposition:

(P) The operation of the most perfect being is always most perfect

And it follows from (P) that God, if he exists, necessarily creates the best possible world. Or at least it does if we make the assumption that the so-called 'no best world' objection is false. The 'no best world' objection simply states that for any possible world that might be termed the best, there is always another that is better. Despite the

\footnotetext{
${ }^{1}$ Cf. Lawrence Resnick, 'God and the best possible world,' American Philosophical Quarterly 10 (1973), 313; Jerome A. Weinstock, 'Must God create the best world?,' Sophia 14 (1975), 37-38; R. W. K. Patterson, 'Evil, omniscience and omnipotence,' Religious Studies 15 (1979), 2; David Basinger, 'Must God create the best possible world? A response,' International Philosophical Quarterly 20 (1980), 341; C. Mason Myers, 'Free will and the problem of evil,' Religious Studies 23 (1987), 291; Michael J. Coughlan, 'Must God create only the best possible world?,' Sophia 26 (1987), 15; David Schrader, 'Evil and the best of possible worlds,' Sophia 27 (1988), 27; Stephen Grover, 'Why only the best is good enough,' Analysis 48 (1988), 224; Charles B. Daniels, 'God vs. less than the very best,' Sophia 35 (1996), 21; Erik J. Wielenberg, 'A morally unsurpassable God must create the best,' Religious Studies 40 (2004), 57. For contrary views see Charles Journet, The Meaning of Evil (London 1963), 104; Robert Merrihew Adams, 'Must God create the best?,' Philosophical Review 81 (1972), 317; Bruce Reichenbach, 'Must God create the best possible world?,' International Philosophical Quarterly 19 (1979), 208; Richard Swinburne, The Existence of God (revised edition, Oxford 1991), 114. It should be noted that those who deny that God must make the best are also those who argue that the notion of the best possible world is incoherent.
} 
popularity of this argument, I believe it to be mistaken. As I have stated the grounds for my belief elsewhere, ${ }^{2}$ I shall not rehearse them again here. I can therefore only ask the reader to assume with me that the 'no best world' objection is false.

Now having the conclusion that God necessarily produces the best possible world might seem to be a boon to the optimist, for it provides him with a cast-iron guarantee that if a perfectly good God exists then the world such a God would create would be the best. But it is in fact a problematic conclusion, for if God necessarily creates the best possible world then technically the best possible world is in fact the only possible world, since all other 'possibles' are not really possible at all. As Mark Heller puts it, 'God, being necessarily all good, cannot do less than best. Any description of a world that includes God's doing something less than the best does not describe a possible world at all. ${ }^{3}$ And herein lies a further problem - if there is only one logically possible world then that world can hardly be described as the best possible world. For as Lawrence Resnick observes, '[t]echnically, if no lesser worlds are possible, our world cannot be the best. There cannot be a superlative where comparatives are impossible. ${ }^{4}$ We can distil these points into the following deductively valid argument:

P1: If God decides to create then he will of necessity create the best possible world. P2: If God will of necessity create the best possible world, then only the best possible world is possible.

P3: If only the best possible world is possible, then it is not the best possible world (as there are no other possible worlds to compare it to).

P4: If the best possible world is not the best possible world, then it is impossible for God to create it.

Therefore if God decides to create it is impossible for him to create the best possible world.

A little explanation is required here. First, by 'possible world' I understand a completely determinate and contingent set of things that are connected spatiotemporally and free from internal contradiction (so on this definition God is not part of any possible world). ${ }^{5}$ Second, I have added an antecedent to P1 to recognise the common theistic claim that it is open to God whether to create or not; P1's consequent, along with P2 and P3, will be familiar from what we have discussed in this paper thus far, while $\mathrm{P} 4$ derives from the generally accepted view that God cannot bring about contradictory states of affairs. It should be clear enough that not only is the conclusion anathema to the optimist, but to theism generally. For we know from P1 that if God decides to create he will of necessity create the best possible world, and from the conclusion that it is impossible for him to create the best possible world. So

\footnotetext{
${ }^{2}$ See my 'Determining the best of all possible worlds', forthcoming.

${ }^{3}$ Mark Heller, 'The worst of all worlds,' Philosophia 28 (2001), 263. See also J. F. Ross, 'Did God create the only possible world?,' Review of Metaphysics 16 (1962), 14, and Coughlan 'Must God create only the best possible world?,' 15.

${ }^{4}$ Lawrence Resnick, 'God and the best possible world,' American Philosophical Quarterly 10 (1973), 315 .

5 This definition is similar to those given by, amongst others, John D. McHarry, 'A theodicy', Analysis 38 (1978), 132, Patterson 'Evil, omniscience and omnipotence', 1-2, and Peter Forrest, 'The problem of evil: two neglected defences', Sophia 20 (1981), 50. I think it is reasonable not to count God as part of any possible world because presumably he himself would not do so. For when deciding what to create, God is surely concerned only with the goodness of what he is creating (or what he is going to create), rather than the goodness of himself plus his creation.
} 
in order to avoid the unfortunate situation that would arise from his positively deciding to create something impossible, he would obviously have to decide not to create at all. Thus the existence of a world is incompatible with that of a perfect God. Yet we know that there is a world! For obvious reasons I will therefore call the above argument the repugnant argument. How to escape its conclusion shall be the focus of the remainder of this paper.

\section{Possible solutions I: God and omnipotence}

It might appear that P1 can be undermined simply by appealing to God's omnipotence, which is typically taken to be the power or ability to do or bring about anything that it is logically possible to do or bring about. ${ }^{6}$ This is ordinarily supposed to cover a great many things, so to insist that the only logically possible action for God is to create one particular world will entail that his omnipotence will be circumscribed in a way not normally considered acceptable.

On the surface, then, the traditional account of omnipotence appears to entail that other worlds beside the best are possible. From which, we might suppose that we can force through the conclusion that the best possible world is not the only possible world on the grounds that to say otherwise would destroy the concept of God. The principal problem with this reasoning, however, is that we are only able to argue that God's omnipotence allows him to create worlds other than the best by considering omnipotence in isolation from all the other divine attributes. Once it is properly considered in conjunction with omniscience and perfect goodness, we see that no world other than the best is possible because God's power is directed by his perfect goodness, which in turn is directed by his perfect wisdom, with the result that he can only consistently will the best possible world. It is thus worthwhile stressing why exactly there is only one logically possible action open to God: his perfect nature.

Is there perhaps a little room for manoeuvre here though? That is, although we have no choice but to accept that God's omnipotence must in practice be directed by his knowledge and goodness, is it not still open to us to suppose that in theory it might not be so directed? Or to put it another way, can we not reintroduce the Scholastic distinction between God's potentia absoluta and his potentia ordinata, i.e. his absolute power (considered in isolation from his other attributes which would otherwise regulate it) and his regulated power? If this distinction is made then it can be argued that although God necessarily creates the best, other worlds are nevertheless possible because it is within God's power to create them even if he lacks the imperfect will that would allow him to do so. Or to put it another way, a distinction can be drawn between what God literally cannot do, and what he cannot bring himself to do. This distinction seems to hold good in everyday life, for it is one thing to say that I literally cannot harm someone (because, say, I am paralysed and so lack the means to inflict harm on anyone) and quite another to say that I cannot bring myself to harm someone (which implies that I have the power to do so, but not the

\footnotetext{
${ }^{6}$ Although omnipotence is popularly understood this way, this is by no means the only sense in which it is understood. There are in fact great disagreements about what an omnipotent being can and cannot do, and consequently about what omnipotence essentially is. To enter into this debate here would involve a long and unnecessary digression to plot all the moves and counter moves, so I shall simply point the reader in the direction of some recent works that contribute to this debate. See Nelson Pike, 'Omnipotence and God's ability to sin,' American Philosophical Quarterly 6 (1969), 208-216; Peter Geach, 'Omnipotence,' Philosophy 48 (1973), 7-20, Thomas V. Morris, Our Idea of God (Notre Dame 1991) Ch. 4, and Wes Morriston, 'Omnipotence and necessary moral perfection,' Religious Studies 37 (2001), 143-160.
} 
will). It seems no less legitimate to transfer this analysis to God to say that while God's power extends to performing actions less than the best, it is only his will that does not. And if this is the case, then as it is affirmed that God has the power to create worlds other than the best, these worlds must therefore be possible.

As promising as this seems, however, it overlooks one very important point, namely that in God's case the fact that he cannot bring himself to do certain things (i.e. anything less than the best) is a logical truth, whereas with humans it is not. As such, there is simply no distinction between what God cannot do and what he cannot bring himself to do. To illustrate, let us return to the above example where a distinction was drawn between my being unable to harm someone and my not being able to bring myself to harm someone. Now the fact that I cannot bring myself to harm someone today does not necessarily mean that I won't be able to bring myself to harm someone tomorrow. I could, overnight, be corrupted, brainwashed, undergo a personality change, or even just happen upon a reason that makes me believe that harming people is acceptable in certain circumstances. In short, the attributes I have, which determine what I can and cannot bring myself to do, are fluid, they can change over time. With God this is not so. And if an agent necessarily cannot bring itself to do a certain action, then it can reasonably be said that the agent simply cannot perform that action. The Scholastic distinction thus does not help us one jot.

\section{Possible solutions II: God's freedom and indifferent choice}

Although the appeal to omnipotence does not help us reject P1, perhaps having recourse to another of God's attributes might, namely his freedom. On the surface it certainly doesn't look like a particularly promising approach; after all, we know that if God decides to create he is bound by his own nature to choose the best possible world, so any appeal to God's freedom would seem to be of no avail because he does not have the freedom to create just anything. Kant saw this only too clearly (during his optimistic phase at any rate), and he rejected all suggestion that God has the "fictitious notion of freedom" that would allow him to choose the worst over the best. ${ }^{7} \mathrm{He}$ thus preferred instead to praise "the benevolent necessity, which is so favourable to us, and from which there can be nothing but the best. ${ }^{8}$ If he had said 'from which there can be nothing or the best' he might have got it right. In any case, invoking God's freedom does nothing to neutralise the repugnant argument. Or so it seems.

Joshua Hoffman and Gary Rosenkrantz appear to agree with P1 - they accept that God is obliged to obey his own nature and make a world of unsurpassable goodness if he is to create at all - but nevertheless feel that it is still possible to appeal to God's freedom in order to render false $\mathrm{P} 2$, that the best possible world is the only possible world. ${ }^{9}$ Their argument hinges on there being 'indefinitely many maximally good possible worlds.' With this supposed, they move on to claim that creating any one of these maximally possible good worlds is 'equally rational for God' and that only one of them can obtain. Now,

\footnotetext{
${ }^{7}$ Immanuel Kant, Theoretical Philosophy 1755-1770 (trans. \& ed. David Walford, \& Ralf Meerbote, Cambridge 1992), 75.

${ }^{8}$ Kant, Theoretical Philosophy 1755-1770, 76.

${ }^{9}$ It should be noted that their argument is in fact intended to defend the idea of divine freedom rather than invalidate the repugnant argument as such. However, as they claim that God can only be free if he is able to do otherwise than he does, i.e. if he is not restricted to creating one particular world, their argument is as much against P2 as it is in favour of divine freedom.
} 
'Since there can be no reason for God to prefer creating any one of these worlds, and since it seems possible for him to create any one of them without his being compelled or determined to do so...We conclude that in creating one of these worlds, God has it within his power (in the libertarian sense) to create any of the alternative possible worlds. In other words, God has it within his power to do otherwise in the requisite sense. ${ }^{, 10}$

Now we might wonder whether there are indeed indefinitely many maximally good worlds, as Hoffman and Rosenkrantz suppose. They argue that this is indeed the case, since 'different goods combined in different possible ways may constitute different, logically independent, possible total goods of the same value. ${ }^{11}$ They illustrate this claim with a character called Smith, who in one possible world has spaghetti for dinner, while in another, ceteris paribus, has linguini. The enjoyment from Smith's eating spaghetti is assumed to be equal to his enjoyment gained from eating linguini, making it the case that there are at least two possible worlds exemplifying the same degree of goodness. What Hoffman and Rosenkrantz fail to ask, however, is how plausible it is that possible worlds might differ only in the tiny detail of what one person has for dinner on one particular night. While others have agreed with them that some possible worlds might differ only in such a detail, ${ }^{12}$ it is also a commonly held view that any difference between worlds that share a common history up to a particular point of time will ultimately lead to significantly different histories. Even something as apparently trivial as the deviation in the direction of an atom is often considered an event sufficient to ultimately produce two radically different worlds. If we are being asked to accept that worlds can differ only in tiny details that do not affect their overall value, we are entirely justified, I think, to ask for a reason why these differences do not multiply over time. For if they do, it is plausible to suppose that they will ultimately lead to worlds of differing value - precisely the opposite of what Hoffman and Rosenkrantz suppose. Until further analysis on this matter has been carried out, I am inclined to consider it an open question as to whether there would be many worlds of unsurpassable goodness.

This is not to suggest that the Hoffman-Rosenkrantz argument is wholly without merit. In fact, if we modify the repugnant argument to allow for their suggestion that there are multiple possible worlds of equal goodness, we will find that we have overcome the problem of there being only one possible world. As great an achievement as this is, however, it does not enable a suitably modified repugnant argument to reach a conclusion more palatable than the one we have already met. For a suitably modified repugnant argument would go as follows:

P1: If God decides to create then he will of necessity create a possible world of unsurpassable goodness.

P2: If God will of necessity create a possible world of unsurpassable goodness, then only possible worlds of unsurpassable goodness are possible.

\footnotetext{
${ }^{10}$ Joshua Hoffman \& Gary S. Rosenkrantz, The Divine Attributes (Oxford 2002), 175-6. The same argument, albeit in a slightly less elegant form, can also be found in Resnick, 'God and the best possible world,' 316 .

${ }^{11}$ Hoffman \& Rosenkrantz, The Divine Attributes, 159.

${ }^{12}$ E.g. Stephen Grover, 'Incommensurability and the best of all possible worlds,' The Monist 81 (1998), 655.
} 
P3: If only possible worlds of unsurpassable goodness are possible, then they are not possible worlds of unsurpassable goodness (as there are no possible worlds of an inferior degree of goodness to which they could be compared).

P4: If possible worlds of unsurpassable goodness are not possible worlds of unsurpassable goodness, then it is impossible for God to create any of them. Therefore if God decides to create it is impossible for him to create a possible world of unsurpassable goodness.

We thus need to look elsewhere for ammunition in our fight against the repugnant argument.

\section{Possible solutions III: we know that things might have been otherwise}

Perhaps it could come from J. F. Ross, who argues that P2 is absurd, conflicting as it does with our knowing that things could have been otherwise than they are:

'[W]e know that things other than what is actual are possible, and we will allow no argument to convince us of the contrary. We would more readily reject the proposition that God exists or that God is absolutely perfect or that every possible world contains God as an element, than we would the obvious consistency of some false proposition. ${ }^{13}$

But this appeal to our certainty that things could have been different is a puzzling one. Are we really certain that things could have been different? Ross obviously thinks so, and damns the denial of his position as 'an obvious falsehood,' but unfortunately neglects to share his reasons for thinking this. ${ }^{14}$ I suspect, however, that he had in mind something akin to an argument first formulated (so far as I know) by Leibniz.

Leibniz did not deny that God's perfect nature was such as to make it inevitable that he would create the best possible world, but argued that although 'God does not fail to choose the best,' nevertheless he could not have been necessitated to do so. ${ }^{15}$ This could be shown, he thought, in the following way:

If God acts out of necessity, then the best possible world is necessary If the best possible world is necessary, then it is the only possible world The best possible world is not the only possible world Therefore God does not act out of necessity.

Or in his own words:

'although it is certain and inevitable that God always chooses the most perfect, whether in fact the best, or most expedient to his own glory...nevertheless it is not for that reason necessary, otherwise it would follow that nothing is possible except that which is actually created, whereas there are infinite possibles (certainly whatever does not imply contradiction) which are not chosen by God. Although God must always choose the best ... nevertheless he chooses freely

\footnotetext{
${ }^{13}$ Ross, 'Did God create the only possible world?,' 23.

${ }^{14}$ Ross, 'Did God create the only possible world?,' 25.

${ }^{15}$ G. W. Leibniz, Theodicy (trans: E. M. Huggard, Chicago 1990), 148.
} 
because that which he does not choose remains possible by its own nature, and so its opposite is not necessary. ${ }^{, 16}$

Leibniz' rejoinder to the repugnant argument thus hinges, as does Ross', on claiming that worlds other than the best are possible. Let us see if this argument fares better than the others.

Leibniz' favoured test to determine logical or absolute necessity was to consider a state of affairs and ask if its opposite implied a contradiction. If it did (and only if it did), the state of affairs was logically necessary. With worlds other than the best, Leibniz thus holds that they should properly be treated as possible worlds since, in and of themselves, they do not imply contradiction. As he explained to Gabriel Wagner, 'There are as many series of things that can be imagined not implying contradiction as there are possible worlds... [F] or I call possible that which does not imply contradiction. ${ }^{17}$ Or in the Theodicy:

'since there are many things which have never happened and never will happen, and which nevertheless are clearly conceivable, and imply no contradiction, how can one say they are absolutely impossible?'18

So Leibniz deems a world possible if it is internally coherent, i.e. if it is in itself free from inconsistency. Leibniz thus attempts to finesse the problem we have been addressing by accepting that only one world could have been made by God, but denying that this entails the impossibility of any other worlds:

'Speaking in absolute terms, it must be said that another state [of things] can certainly exist, but nevertheless the present one does exist, because from the nature of God it follows that he prefers the most perfect. ${ }^{\text {, }}$

To the best of my knowledge Leibniz nowhere comes closer to explicitly employing the old Thomistic distinction between absolute and relative possibility than he does here. In Thomas' philosophy, a thing or state of affairs can be said to be absolutely possible if it is internally consistent, i.e. involves no contradiction, and relatively possible if some agent or other being could actually bring it about, i.e. supply the means of generation for it. ${ }^{20}$ If Leibniz accepts this distinction then we would expect to find him affirming that (a) lots of things and series of things are possible in the absolute sense, and (b) the best world and its contents are the only things possible in the relative sense, i.e. with respect to God (because God can only create the best possible world). And this is precisely what we do find. We have already seen that Leibniz considers many non-existing things to be possible in the absolute sense because in and of themselves they are free from contradiction. ${ }^{21}$ But just as readily as he affirms the absolute possibility of non-existing things, he also affirms that the best world is the only one possible in relation to God. This occurs in the passage cited

\footnotetext{
${ }^{16}$ G. W. Leibniz, Textes Inédits (ed. Gaston Grua, Paris 1948), 299-300. Translations from this volume are my own.

${ }^{17}$ Leibniz, Textes Inédits, 390.

${ }^{18}$ Leibniz, Theodicy, 272. Cf. Leibniz, Textes Inédits, 289 and 324; Leibniz, Theodicy, 234-5.

${ }^{19}$ Leibniz, Textes Inédits, 393.

${ }^{20}$ Cf. Aquinas, Selected Philosophical Writings (trans. \& ed. Timothy McDermott, Oxford 1993), $244-$

5 (originally from Quaestiones Disputatae de Potentia). Aquinas appears to have developed the distinction from Aristotle's Metaphysics 1019b21-1020a6.

${ }^{21}$ Cf. Leibniz, Textes Inédits, 287-88.
} 
above, where Leibniz accepts that worlds other than the best are possible in an absolute sense, but not in a relative sense 'because from the nature of God it follows that he prefers the most perfect. ${ }^{22}$ And in a short text entitled De Libertate (On Liberty) from the early 1680 s, in which Leibniz plays out an imaginary discussion on necessity and possibility, he considers a question posed by his imaginary interlocutor that God cannot will a thing to exist unless it is part of the best series, and replies: 'I accept this, nevertheless it remains possible in its own nature, even if it is not possible with respect to the divine will. ${ }^{23}$

Before we assess the merits of Leibniz' solution, it is worth making the following observation: although Leibniz is happy to grant that a thing or state of affairs is possible if its concept harbours no contradiction, this does not mean that he is prepared to accept that it could actually exist. Strictly speaking, things or states of affairs not belonging to the best world are incompatible with God's existence, as he concedes in a series of notes from the early 1680 s:

'the eternal damnation of an innocent man seems to be from that number of things of which the essence does not in fact imply contradiction because it can be completely understood, but nevertheless its existing implies contradiction. ${ }^{24}$

'That number of things' is in fact very large, and encompasses anything that is (a) not part of the best series, and (b) involves no contradiction in and of itself. Hence such things are possible, in Leibniz' accepted sense, but can nevertheless never exist, for if God were to produce them it would generate a contradiction. The concepts of uncreated possible things therefore contain no contradictions so long as they remain uncreated, which is to say that they must necessarily remain uncreated. We must be wary, then, of assuming that when he spoke of 'possible things' he meant things that could actually exist, as evidently this is not what he meant at all. ${ }^{25}$

The question before us now is whether Leibniz' analysis is sufficient to assuage our concern that the best possible world is the only possible world, and as such not actually the best possible world at all. We might be tempted to suppose that it is, as his notion of 'possible' has been very warmly received by philosophers. Indeed, if we were to say 'a unicorn is possible and a round square is not' we would ordinarily be understood to be talking about concepts, and whether the terms of those concepts were compatible with each other. We would be quite surprised, I think, if someone interpreted our statement as suggesting a unicorn is part of the best world which God must produce whereas a round square is not. Likewise, when it is asked whether God is possible or not, as it often is by philosophers of religion, the question is understood

\footnotetext{
${ }^{22}$ Cf. Leibniz, Textes Inédits, 390.

${ }^{23}$ Leibniz, Textes Inédits, 289. If Leibniz did indeed accept the distinction between absolute and relative possibility, as I maintain he did, why is it that he fails to use the term 'relative possibility'? The answer is to be found in De Libertate, where Leibniz explains that he reserves the term 'possible' for things 'possible in their own nature,' i.e. the absolutely possible, so as to avoid giving the word 'every kind of absurd locution.' (Leibniz, Textes Inédits, 289) With the notion of relative possibility stripped of the right to determine what is and is not 'possible' in Leibniz' favoured sense, we see precisely how he feels he can get away with claiming that worlds other than our own are possible even though God could never make them.

${ }^{24}$ Leibniz, Textes Inédits, 300.

${ }^{25}$ The point is important, for as Leibniz notes 'possible things have no existence at all and therefore have no power to make themselves exist, and consequently it is necessary to look for the choice and cause of their existence in a being whose existence is already established and therefore necessary in itself.' Leibniz, Textes Inédits, 286.
} 
to be asking whether the attributes normally ascribed to God are consistent with each other, not whether there is some agent able to promote God from the nothingness of non-being to actuality. We might feel entitled to say on the strength of this that worlds other than the best are still possible in their own nature even though God could never make them, and therefore that it is acceptable to speak of the best possible world.

However Lawrence Resnick notes that this kind of solution 'is patently ad hoc, for, except to escape a paradox, no one would ever suppose that a world which could not possibly exist is a possible world. ${ }^{\prime 26} \mathrm{He}$ accepts that the traditional idea of possibility turns on internal logical consistency alone, but argues that this test for possibility is no longer valid when a 'necessarily existing Perfect Creator' is supposed. ${ }^{27}$ What he is getting at here, I think, is that if we are to suppose a perfect God then we must revise our notion of possibility. For a thing to be possible it would no longer be enough that it is absolutely possible in the sense described above, it would have to be relatively possible too, i.e. it must be free from logical inconsistencies and God must be able to make it. If neither condition is met, then the thing is not truly possible in the important sense that it could actually exist. It seems to me that this must be right. To insist that a thing which could never exist is nevertheless possible seems an unforgivable abuse of language. Indeed, it leaves no clear water between what is possible and what is impossible. ${ }^{28}$ It seems, then, that Leibniz' efforts to establish that worlds other than the best are genuinely possible cannot be considered successful.

\section{The best possible world}

We have thus far found no chinks in the repugnant argument, and given its tightly logical nature it would seem that there are none for us to find. However there is a solution that can pull the fangs from the repugnant argument, though it extracts a price from the optimist too. It emerges when we recognise that the repugnant argument is predicated on one huge historical mistake, one for which we have Leibniz to thank. The mistake to which I allude is the notion of the best possible world, bequeathed to us by Leibniz. We shall be able to appreciate the scale of his blunder by returning to the point I made in the previous section, that different criteria for determining possibility apply in theistic and non-theistic contexts. In the latter it is sufficient that the concept of a thing is free from contradiction for it to be deemed possible. In the former, because a perfect God is being supposed, and because in this context God alone determines what can and cannot exist, it is necessary but not sufficient for the concept of a thing to be free from contradiction for it to be deemed possible. In addition to that, God must also be able to make the thing. Leibniz' mistake was to employ the former conception of 'possible' when he should have employed the latter (because he was supposing the existence of a perfect God). Had he not made this error, he would have realised that the notion of 'the best possible world' was only meaningful (ironically enough) in a non-theistic context, for only

\footnotetext{
${ }^{26}$ Resnick, 'God and the best possible world,' 315.

${ }^{27}$ Resnick, 'God and the best possible world,' 314.

${ }^{28}$ The argument here, developed from Resnick, clearly undermines the distinction drawn by Alvin Plantinga between possible worlds and actualizable worlds. In Plantinga's thought, a possible world is "any possible state of affairs that is complete," whereas an actualizable world is a possible world that God is able to bring about. For reasons I shall not go into here, Plantinga argues that not all possible worlds are actualizable worlds, and as a result he thinks it may well be the case that the possible world featuring moral good but no moral evil is not actualizable despite being possible. But what he overlooks is the curious abuse of language involved in reaching this conclusion, as it is unclear how unactualizable possible worlds can be called possible at all given that they could never exist. The quotation is from Alvin C. Plantinga, God, Freedom and Evil (Grand Rapids, 1977), 36.
} 
there is it meaningful to talk of possible worlds in the plural, and thus only there can possible worlds be compared and superlatives applied. Once we move to a theistic context and suppose the existence of a perfect God, the notion of the best possible world becomes nonsensical because a different formula for determining possibility applies. Under this formula, only what is free from contradiction and consistent with God's existence is possible. And we know from proposition $(\mathrm{P})$, which we encountered near the start of this paper, that God, as a perfect being, will necessarily act in the most perfect way - something Leibniz knew only too well. ${ }^{29}$ So we know that only what is best or most perfect is consistent with God's existence. Now in first premise of the repugnant argument we construed this to mean the following:

\section{P1: If God decides to create then he will of necessity create the best possible world.}

Now given what was said above, it should be clear that the idea of God (a necessary being) creating necessarily is in conflict with the idea of the best possible world (which of course is just a shorthand way of saying 'the best of all possible worlds'). The conflict comes to a head later in the repugnant argument, where it is affirmed that the best possible world is not really the best possible world at all - a clear breach of the law of identity. This contradiction could have been avoided by recognising that the criterion of possibility employed in the notion of 'the best possible world' is the wrong one for the context. What we now know is that, for that notion to make any sense at all, there must be at least two possible worlds with different degrees of merit. And what we have also learned is that when a perfect God is posited, this requirement is not, indeed cannot be fulfilled, because a perfect God necessarily acts in the most perfect way, thus condemning all but one world to be eternally impossible.

There are two questions that now deserve our attention. First, what should P1 have said in place of 'the best possible world'? And second, why did we use the notion of the best possible world in the first place? The easy answer to the second question is of course that it is a popular concept and expression, not one generally considered to be problematic. We shall return to this shortly. Turning, then, to the question of what P1 ought to have said, one answer is: that God will of necessity create the only possible world. But a second - and better - answer emerges when we remind ourselves why there is only one possible world: firstly, because God is perfectly good, and secondly, because the world he favours is unsurpassed by any other. 'Unsurpassed by any other what?' we may ask, for we know that there are no other possible worlds. The response is disarmingly simple: unsurpassed by any other worlds. Not possible worlds. Worlds. While the only possible world cannot be the best of all possible worlds, it is still the best world, or best of worlds, and we thus have our answer: the world God necessarily creates will not be the best of all possible worlds, but it will be the best world.

Therefore God necessarily selects for creation the best world and only that world meets the applicable criteria for being possible. All the worlds inferior to the best are impossible by the same criteria, for while they are internally consistent, they have no chance of ever being granted existence. Had Leibniz recognised this he would not have spoken of the best possible world at all; he would instead have talked of the best world, as indeed would the writers that followed him (since they all borrowed the concept and phrase 'the best possible world' from him). ${ }^{30}$

\footnotetext{
${ }^{29} \mathrm{Cf}$. Leibniz, Textes Inédits, 286 and 393.

${ }^{30}$ How much of the blame should be directed Leibniz' way for this is debatable. As Radner and Radner have observed, Leibniz does not use the expression 'the best of all possible worlds' in his work. Nevertheless his writings are littered with alternative renderings of the same idea, such as 'the best of
} 
It is thus something of an historical accident that the phrase 'the best possible world' (or 'the best of all possible worlds') came to be preferred over 'the best world' (or 'the best of worlds'). Had Leibniz not tried to wriggle out of accepting the necessity of God's creation by insisting on a definition of 'possible' that was only half right given the context in which he was writing, the chances are the phrase 'the best possible world' would not have been popularised in the way that it has. But as untold numbers of philosophers right up to the present day have followed Leibniz and committed his mistake again and again, the meaningless notion of 'the best possible world' has earned itself an unwarranted place in the philosopher's vocabulary. And an appearance in the soon-to-be-discredited repugnant argument.

But before we see how amending Leibniz' mistake can tame the repugnant argument, we ought to be certain that the amendment I have suggested - ditching the concept of 'the best possible world' in favour of 'the best world,' at least in theistic contexts - is a valid step. For it is surely not enough that we need to take it in order to lay low the repugnant argument; it also needs to be reasonable in itself. And I think that it is, for in a theistic context a 'world' need simply be considered analogous to what in a non-theistic context is commonly termed a 'possible world'. That is, it is a completely determinate and contingent set of things that is free from internal contradiction. Now I submit that there is no absurdity in the idea that such things can be compared with each other and even arranged in order of merit. For even though the vast majority of these worlds are not possible (because God cannot make them) they are still worlds, i.e. alternative determinate histories harbouring no contradiction, no less than is the best of their number.

This is challengeable of course. For how can it be meaningful to compare a possible thing with other things that aren't possible at all? Is it not just as absurd as saying that a square can be compared in size with a square triangle? Both cases turn on comparing the possible with the impossible, and if the latter case is absurd then why not also the former?

This objection is interesting, but not particularly telling, because it confuses two distinct types of impossibility. In the case of the square and the square triangle, we must recognise why exactly there is no scope for comparison: because a square triangle does not describe a coherent concept. By its very definition, then, it is not the sort of thing that can have a size or any other properties. Comparing a square triangle with anything is thus out of the question. In the case of worlds, there are two ways in which they could be impossible. The first way is when a world is like the square triangle in nature, that is, it involves contradiction. Such worlds may include and exclude the same thing, or involve some other breach of the laws of logic. It is clearly no more acceptable to compare these sorts of impossible worlds with a possible world than it is to compare a square triangle with a square, for the same reason that we have ruled out the latter (i.e. these impossible 'worlds' do not actually describe anything and can therefore be said to not really be worlds at all). But there is of course another way in which a world can be impossible: not because of some violation of a logical

\footnotetext{
all possible universes' (Leibniz, Theodicy, 249) 'the best possible plan' (Leibniz, Theodicy, 188 and 190) and 'the best possible series.' (G. W. Leibniz, Monadology and other Philosophical Essays (trans. Paul Schrecker \& Anne Martin Schrecker, Indianapolis 1965), 131) Moreover, Leibniz says of God that he matches 'all things together in the best way possible' (Leibniz, Textes Inédits, 287) and 'always chooses the best possible.' (G. W. Leibniz, Die Philosophiscen Schriften III (ed. C. I. Gerhardt, Berlin 1875-90), 587, cf. Leibniz, Theodicy, 187) Given these remarks it is hardly surprising that the concept and expression 'the best of all possible worlds' have been associated with him. See Daise Radner \& Michael Radner, 'Optimality in biology: Pangloss or Leibniz?,' The Monist 81 (1998), 684 n8.
} 
rule within the concept of the world itself, but rather because these worlds are inferior to the best, and thus not attractive enough to a perfect being to make him want to create them. Thus it is the very fact that these impossible worlds can be compared to the only possible world that makes them impossible in the first place! If we deny that these impossible worlds can be compared to the one possible world then there is absolutely no reason at all why these worlds should be impossible, as in themselves they contain no contradiction. And if it is acceptable to compare the only possible world with all the other worlds that it renders impossible by its very superiority, then it is quite acceptable to refer to it as the best world.

Hence the repugnant argument needs to be recast as the following hypothetical syllogism:

P1: If God decides to create then he will of necessity create the best world.

P2: If God will of necessity create the best world, then only the best world is possible. Conclusion: Therefore if God decides to create he will of necessity create the only possible world (i.e. the best world).

By stripping out the reference to 'possible world' in P1 and replacing it with 'world' the argument takes a very different course, and arrives at a conclusion that an optimist would find wholly unrepugnant.

I mentioned that this solution came with a price for the optimist. What this is should be obvious - the optimist cannot call this world the best of all possible worlds, he must instead call it the best world. The latter is not as impressive a moniker as the former, and betrays the fact that there are no other possible worlds that could be inferior to the one God creates. But once it is made clear why there are no other possible worlds, i.e. the supremacy of the best and the perfect goodness of he who chooses it, then the price cannot be considered to be an especially high one to pay. The optimist gets most of what he wants and actually has to give up very little. But best of all, he saves himself from the conclusion of the repugnant argument and gets to part company with a meaningless concept that has persisted for more than 300 years. $^{31}$

\footnotetext{
${ }^{31}$ [Contents of footnote removed so as to enable blind refereeing.]
} 